\title{
Peronismo e revolução: as revistas montoneras
}

\section{Peronism and revolution: the montonero's cultural magazines}

Thiago Prates ${ }^{1}$

Resenha de: SLIPAK, Daniela. Las revistas montoneras: cómo la organización construyó su identidad a través de sus publicaciones. Buenos Aires: Siglo Veintiuno Editores, 2015.

Resenha recebida em: 20/03/2018

Resenha aprovada em: 29/10/2018

As lutas armadas e os projetos políticos das esquerdas latino-americanas contemporâneas são temas vastamente trabalhados pela historiografia. A opção pelo uso da violência como instrumento político para a tomada do poder, fortalecida na América Latina a partir da vitória da experiência cubana em 1959, recebeu grande atenção de acadêmicos, que analisaram a constituição dos grupos, suas táticas e estratégias, seus fundamentos políticos, publicações e discursos, bem como a repressão às suas ações e, finalmente, os seus fracassos.

No caso argentino, agrupações como os Uturuncos, as Forças Armadas Revolucionárias (FAR), as Forças Armadas Peronistas (FAP), o Exército Revolucionário do Povo (ERP) e os Montoneros foram amplamente estudadas pela academia nacional. A partir da redemocratização argentina, este último grupo recebeu especial atenção da intelectualidade. Se naquele período, a década de 1980, os montoneros foram tratados como vítimas do último regime militar daquele país, posteriormente as análises vieram a se tornar mais complexas.

Na década mencionada, os discursos na esfera pública distanciavam os montoneros de seu compromisso político e buscavam evidenciar a sua condição de indivíduos afetados pela chamada guerra suja e pela violência paraestatal. Entretanto, destacam-se obras que aprofundam os exames sobre os ex-combatentes. Como exemplos, Soldados de Perón, de Richard Gillespie, publicado em 1982 e traduzido

\footnotetext{
${ }^{1}$ Graduado e mestre em história pela Universidade Federal de Minas Gerais (UFMG), Brasil. Atualmente cursa doutorado em história na mesma instituição. E-mail: thoprates@gmail.com
}

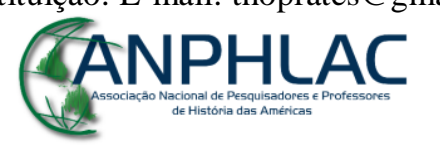

Revista Eletrônica da ANPHLAC, ISSN 1679-1061, №. 25, p. 303-311, Jul./Dez., 2018.

http://revista.anphlac.org.br 
para o espanhol em 1987 (GILLESPIE, 2011), ainda importante para os estudos sobre sua organização, estrutura, seus militantes, ações e ideários, e Perón o muerte, de Silvia Sigal e Eliseo Verón, publicado em 1986 e reeditado em 2003 (SIGAL; VERÓN, 2003), que se debruça não apenas sobre o discurso peronista, mas também sobre as enunciações da Juventude Peronista, organização próxima aos Montoneros e que frequentemente alimentou a guerrilha com militantes políticos, apoiadores e mesmo combatentes. Por fim, incorporam-se ainda entre as obras importantes para compreender criticamente a opção armada os livros de Claudia Hilb e Daniel Lutzky, La nueva izquierda argentina: 1960-1980 (política y violencia) (HILB; LUTZKY, 1984) e o relato de Pablo Giussani, militante de esquerda crítico aos montoneros, Montoneros. La soberbia armada (GIUSSANI, 1984).

O decênio seguinte, 1990, foi marcado por uma perspectiva militante que buscava restituir as identidades apagadas das vítimas das ações paramilitar e estatal, ao passo que também incorporava uma autocrítica e reconhecimento dos erros dos antigos combatentes, um verdadeiro balanço sobre a derrota do projeto revolucionário, justamente em um momento em que a queda da União Soviética obrigava a esquerda a se repensar. Com o intuito de resgatar os sujeitos históricos, aparecem obras como os três grandes volumes de La voluntad. Una historia de la militancia revolucionaria en la Argentina (ANGUITA; CAPARRÓS, 2013), publicados entre 1997 e 1998, mas também trabalhos que buscavam analisar a violência revolucionária, como Argentina's Lost Patrol (MOYANO, 1995).

Posteriormente, a academia argentina paulatinamente abandonou as perspectivas maniqueístas, bem como categorias de vítimas e heróis, para compreender o projeto político montonero e a escolha pela violência como instrumento de ação no espaço público. Destacamos as reflexões de Horacio Tarcus, La secta política. Ensayo acerca de la pervivencia de lo sagrado en la modernidad e Notas para una crítica de la razón instrumental (TARCUS, 1998-1999 e 2006), de María Matilde Ollier, Golpe o revolución (OLLIER, 2005), assim como o trabalho recente de Sebastián Carassai, Los años setenta de la gente común, relativizando o consenso sobre uma peronização das classes médias nos anos 1960-1970, bem como o suposto apoio à violência armada (CARASSAI, 2013).

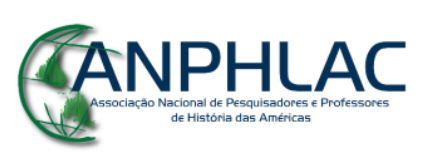

Revista Eletrônica da ANPHLAC, ISSN 1679-1061, №. 25, p. 303-311, Jul./Dez., 2018.

http://revista.anphlac.org.br 
O trabalho de Daniela Slipak, Las revistas montoneras: como la organización construyó su identidade a través de sus publicaciones, publicado em 2015 pela editora Siglo XXI, em Buenos Aires, contribui para um aprofundamento na temática. A autora não traz um objeto original, mas trata dos montoneros a partir de outra perspectiva: não busca uma suposta verdade por trás de máscaras e disfarces, de uma prática verdadeira que se oculta em um discurso político, mas procura identificá-los, estudá-los e compreender as suas especificidades a partir das representações sociais produzidas pelo grupo.

Slipak analisa as concepções, os relatos e discursos que marcaram o espaço montonero e outorgaram um sentido coletivo às suas ações. Dada a importância dos aspectos simbólicos na constituição e funcionamento dos grupos, revisitou a organização montonera a partir de sua dimensão identitária. Para tanto, a pesquisadora ligada à Universidad Nacional de San Martín se debruçou sobre sete publicações ligadas aos montoneros: Cristianismo y Revolución (1966-1971), El Descamisado (1973-1974), El peronista lucha por la Liberación (1974), La Causa Peronista (1974), Puro Pueblo (1974), Movimiento para la Reconstrucción y Liberación Nacional (1974) e Evita Montonera (1974-1976). Slipak se concentra em dimensões centrais das identidades políticas, como a instituição das origens e a invenção de uma tradição, a narração prospectiva, o enfrentamento com alteridades, a representação de um âmbito comum e a enunciação de uma norma interna, de um modelo de conduta a ser seguido. A originalidade de sua pesquisa surge aí, na análise de uma identidade montonera.

O livro é divido em cinco capítulos que abordam as publicações em ordem cronológica, de Cristianismo y Revolución, fundada em setembro de 1966 pelo ex-padre Juan García Elorrio, até Evita Montonera, revista montonera publicada clandestinamente entre 1974 e 1979. Progressivamente, ao longo dos capítulos, Slipak introduz temas recorrentes nas publicações, como a violência, os mitos fundacionais, a ligação entre líder e povo, a proeminência de Perón e os modelos de militância.

O primeiro ponto introduzido é o papel da violência na política. Nos balanços historiográficos conduzidos na Argentina construíram-se duas chaves interpretativas sobre o recurso às armas: a do desvio e a do espelho. Ambas postulam a ocorrência de uma transformação qualitativa dos princípios políticos defendidos pelos montoneros em seus princípios. Aqueles que defendem a perspectiva do desvio afirmam que a

\section{CANPHLAC}

Revista Eletrônica da ANPHLAC, ISSN 1679-1061, №. 25, p. 303-311, Jul./Dez., 2018.

http://revista.anphlac.org.br 
organização progressivamente se militarizou e burocratizou ao aumentar cada vez mais as ações armadas, que houve um afastamento entre a cúpula dirigente e a base popular, culpando muitas vezes uma suposta aproximação com o marxismo-leninismo. Os adeptos da teoria do espelho alegam que os montoneros expandiram o uso da violência como forma de combater a violência paramilitar e estatal, uma reação à brutalidade de uma realidade cada vez mais polarizada.

Slipak recusa tais perspectivas e busca entender a "entronização da cúpula burocrática, o crescimento das ações armadas e a decisão de formalizar o exército na metade dos anos setenta; não como desvios novos, mas como processos ligados às características constitutivas do espaço" (SLIPAK, 2015, p.15). A autora mostra como desde Cristianismo Revolución, publicação de um grupo do qual surgiram vários dos que viriam a ser os montoneros, a violência possuía um caráter dual: por um lado era um recurso político viável, uma escolha entre outras possíveis, dado que a revista não abandonava outras formas de ação no espaço público, possuía um caráter instrumental e um valor de método em defesa de um projeto; por outro, era entendida não como um desejo, mas como uma necessidade, como a única forma de romper as estruturas de poder e não se manter cúmplice da opressão, uma reação à violência vinda de cima e, portanto, encarada como uma obrigação desvinculada da noção de responsabilidade. De toda forma, a violência era vista como um meio para solucionar as injustiças. Por fim, a guerra não era pensada como um recurso de exceção, a própria política era concebida a partir de uma lógica bélica.

As outras publicações seguiram essa linha, El Descamisado e Evita Montonera enfatizaram o recurso à violência em um momento em que a Organização expandia suas operações militares, ao passo que Puro Pueblo e Movimiento, publicações advindas de grupos dissidentes dos montoneros, criticaram a crescente militarização e o abandono de outras formas de militância, ainda que jamais tenham renegado a luta armada.

O elemento seguinte analisado por Slipak é a questão da origem, os mitos fundacionais, ponto fundamental para a construção de uma identidade. Todas as publicações mencionadas buscaram suas raízes e inventaram suas tradições a partir do peronismo. As revistas remontaram não somente ao período iniciado a partir de 1945 , mas ao próprio 17 de outubro daquele ano, batizado pelos peronistas como Dia da Lealdade, quando milhares de trabalhadores se reuniram na Praça de Maio, em Buenos

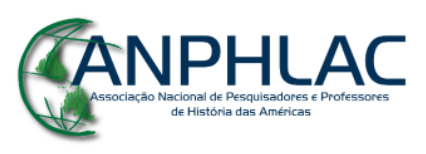

Revista Eletrônica da ANPHLAC, ISSN 1679-1061, №. 25, p. 303-311, Jul./Dez., 2018.

http://revista.anphlac.org.br 
Aires, para exigir a liberdade do líder encarcerado. Esse evento apontaria para conexão direta entre Perón e o povo, componente importante para a constituição da legitimidade política montonera.

As revistas também ergueram sua identidade sob a base da chamada resistência peronista, os inúmeros atos de oposição iniciados no país a partir da queda de Perón, em 1955. Os montoneros criaram uma imagem de um povo combatente que se recusava a aceitar a proscrição do principal movimento político nacional, as suas greves, marchas, cânticos, organizações, ações armadas e o sofrimento causado pela repressão. A representação de uma origem resistente servia para conectar as lutas montoneras do presente a um longo período combativo e enquadrar a organização em um processo popular. Destoante, Movimiento permaneceu mais presa aos símbolos clássicos: recuperou o mito de origem clássico do peronismo de uma classe trabalhadora leal ao líder que lhes concedeu conquistas históricas e mantinha um contato direto com o seu povo, defendeu o sindicalismo e a negociação como instrumento de combate, bem como a normalização política e institucional, rechaçou a concepção vanguardista atrelada ao marxismo-leninismo, condenou o uso da violência após a volta à democracia e se colocou disposta a apoiar o governo peronista e Isabel Perón.

A procura pelas raízes peronistas do movimento leva a refletir sobre a relação dos montoneros com Perón. Daniela Slipak nos mostra que as revistas montoneras, a partir de El Descamisado, mantiveram uma relação dupla e, por vezes, excludente com o caudilho. Obviamente houve o reconhecimento de Juan Domingo Perón como líder do movimento e protagonista do processo de libertação nacional, chefe das massas organizadas e autoridade inquestionável. Movimiento, ligada a Juventud Peronista Lealtad, deu especial enfoque a esse ponto.

Por sua vez, as outras revistas, e os montoneros de forma geral, questionaram a proeminência do velho líder no processo contemporâneo argentino. A proscrição do movimento entre 1955 e 1973, bem como o exílio de Perón, permitiu uma pulverização dos discursos peronistas, uma transformação política e uma flexibilização doutrinária. É conhecida, por exemplo, a ação do poderoso líder metalúrgico Augusto Vandor, posteriormente assassinado pela guerrilha argentina, que defendia a construção de um peronismo sem Perón. Desta maneira, os montoneros articularam um peronismo próximo às vertentes radicais de esquerda que não condiziam com o que defendia o

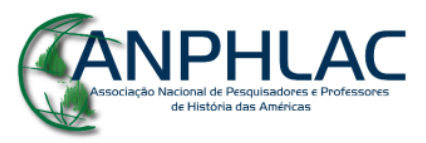

Revista Eletrônica da ANPHLAC, ISSN 1679-1061, №. 25, p. 303-311, Jul./Dez., 2018.

http://revista.anphlac.org.br 
regime peronista inaugurado em 1973. Acusados de infiltrados marxistas pelos setores mais ortodoxos do peronismo, os montoneros tentaram chamar para si a autoridade sobre o movimento, suplantar o próprio Perón. Argumentavam que a burocracia estatal, o sindicalismo corrupto e os políticos mais conservadores impediam o contato do líder com o seu povo. A "teoria do cerco", como foi concebida pela Juventude Peronista, era um dos elementos fundamentais nesse discurso, deslegitimava a palavra Perón ao afirmar que o líder era enganado por aqueles que o rodeavam, o que permitia salvar a imagem simbólica do caudilho e, ao mesmo tempo, criticar a política praticada pelo Estado. Para Slipak, os montoneros, em suas revistas, não deixaram claro se integravam a teoria do cerco: oscilaram entre a percepção de um discurso manipulado e ao mesmo tempo denunciaram os supostos erros de Perón. Após a sua morte e a ascensão de Isabel Perón à presidência, a organização recusou taxativamente a liderança. Tal dualidade foi permanente e permitiu aos montoneros disputar a autoridade sobre o movimento, a palavra do líder e prescindir de sua figura, deslocando o protagonismo político para o povo.

Por fim, Las revistas montoneras ainda traz um tom polêmico. Em sua busca por uma identidade montonera, Slipak paulatinamente constrói uma imagem totalitária do movimento. Fundamentada em autores que se dedicaram ao estudo do totalitarismo, como Hannah Arendt e Claude Lefort, e em intelectuais que refletiram sobre a representação e o corpo político, caso de Rosanvallon, a socióloga analisa o discurso montonero e descreve ao menos dois de seus aspectos totalizantes, ainda que matize tal classificação, sobretudo nas revistas El Descamisado e Evita Montonera. O primeiro seria a pretensão da organização montonera de eliminar não apenas os mecanismos de representação política, o que configuraria uma democracia direta, mas também os próprios procedimentos de construção de uma vontade comum ou geral, o que a autora chama de democracia imediata. Nessa perspectiva, o povo estaria dado, não haveria a necessidade de uma mediação para a sua constituição. Segundo Slipak, "para as revistas, mais que configurar a vontade popular, o pluralismo institucional e as agrupações intermediárias eram uma ameaça para a dualidade peronista, dado que acabariam por corrompê-la. A partir deste ponto de vista, o povo não possuía a necessidade destas instâncias para conformar-se" (SLIPAK, 2015, p . 128). Desta maneira, os montoneros concebiam o povo como um corpo guiado por uma cabeça

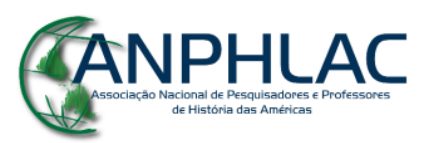

Revista Eletrônica da ANPHLAC, ISSN 1679-1061, №. 25, p. 303-311, Jul./Dez., 2018.

http://revista.anphlac.org.br 
encarregada de tomar as decisões. A organização se percebia como povo, porém mais que o povo. Haveria em ambas as publicações uma concepção de um povo-uno, homogêneo e infragmentável.

O segundo elemento passível de configurar-se como totalizante seria a normatização do comportamento e o estabelecimento de arquétipos de militância. Os montoneros estabeleceram uma lei revolucionária e um código punitivo a ser seguido estritamente, cobraram uma disciplina inquebrantável e exigiram a execução da justiça quando ocorressem transgressões. A organização não apenas criou um princípio político que servia como guia, mas também normatizou a vida afetiva de seus militantes: exigia um cotidiano marital, monogâmico, heterossexual, fiel e familiar (SLIPAK, 2015, p. 205-206). Além disso, as publicações montoneras mencionadas pretendiam padronizar a vida pública e o aspecto íntimo dos combatentes, criar um modelo de pensamento e de sensibilidade. Para Slipak, os montoneros produziram uma sociabilidade de caráter total, uma rede onipresente em torno da organização, sem separação entre público e privado, fundamentada em uma homogeneidade comunitária e na negação da especificidade pessoal. O indivíduo seria uma espécie de homem-engrenagem, nas palavras da autora, que faria funcionar uma organização pautada em princípios de eficiência (SLIPAK, 2015, p. 218-219).

Entretanto há de se ressaltar que esse aspecto também foi permeado por contradições. Cristianismo y Revolución e as publicações dissidentes, Puro Pueblo e Movimiento para la Reconstrucción y Liberación, não adotaram tal perspectiva. Puro Pueblo recorreu a uma concepção vanguardista próxima ao marxismo-leninismo, pretendia trabalhar com o povo, para o povo e junto ao povo, não substituí-lo enquanto corpo político, ao passo que Movimiento se aproximou da concepção clássica de representatividade peronista.

Se o trabalho de Slipak se destaca pela cuidadosa atenção às minúcias dos discursos nas revistas e às suas contradições com a prática cotidiana, bem como pelo diálogo com a bibliografia pertinente, peca pela falta de debate metodológico sobre como trabalhar com as suas fontes, as próprias revistas: não há sequer uma linha em que o assunto seja tratado ou alguma referência bibliográfica em suas notas que discuta o tema. As revistas aparecem como puras fontes de sua pesquisa, não como objetos. A autora se restringe a descrever brevemente seus aspectos físicos, estrutura interna,

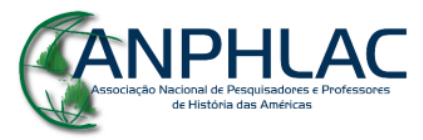

Revista Eletrônica da ANPHLAC, ISSN 1679-1061, №. 25, p. 303-311, Jul./Dez., 2018.

http://revista.anphlac.org.br 
financiamento e a elencar o seu grupo editorial. Não existe a preocupação em pensar as especificidades de um discurso produzido e propagado em um meio material bastante específico, suas possibilidades e restrições ou mesmo o projeto editorial pretendido. Igualmente, os processos de produção e circulação das revistas recebem pouca ou nenhuma atenção de Slipak. O leitor não deve se enganar: o objeto da autora é a Organização, não as suas revistas. Tal lacuna se apresenta como uma oportunidade para futuras pesquisas.

Las revistas montoneras é um trabalho sério, profundo e lúcido sobre um tema que ainda é tratado com cuidado e também polêmica na Argentina contemporânea. Fundamentada em uma grande pesquisa documental em diálogo com a bibliografia adequada, a pesquisa de Slipak é uma grande contribuição para aqueles que estudam a história argentina pós-1955, as esquerdas latino-americanas, os movimentos armados e a violência política em nossa região.

ANGUITA, Eduardo; CAPARRÓS, Martín. La voluntad. Una historia de la militancia revolucionaria en la Argentina. 1966-1973. Buenos Aires: Planeta, 2013.

ANGUITA, Eduardo; CAPARRÓS, Martín. La voluntad. Una historia de la militancia revolucionaria en la Argentina. 1973-1976. Buenos Aires: Planeta, 2013.

ANGUITA, Eduardo; CAPARRÓS, Martín. La voluntad. Una historia de la militancia revolucionaria en la Argentina. 1976-1978. Buenos Aires: Planeta, 2013.

CAMPOS, Esteban. Memorias, ensayos y polémicas. El balance de la experiencia montonera en los años 80. Topoi (Rio J.), Rio de Janeiro , v. 14, n. 26, p. 6-17, Junho2013.

CARASSAI, Sebastián. Los años setenta de la gente común: la naturalización de la violencia. Buenos Aires: Siglo Veintiuno Editores, 2013.

GILLESPIE, Richard. Soldados de Perón. Historia crítica sobre los montoneros. Buenos Aires: Sudamericana, 2011.

GIUSSANI, Pablo. Montoneros. La soberbia armada. Buenos Aires: Sudamericana, 1984.

HILB, Claudia; LUTZKY, Daniel. La nueva izquierda argentina: 1960-1980 (política y violencia). Buenos Aires: CEAL, 1984.

\section{GANPHLAC}


MOYANO, María José. Argentina's Lost Patrol: Armed Struggle, 1969-1979. New Haven: Yale University Press, 1995.

OLLIER, María Matilde. Golpe o revolución. La violencia legitimada, Argentina 19661973. Buenos Aires: Eduntref, 2005.

SIGAL, Silvia; VERÓN, Eliseo. Perón o muerte: los fundamentos discursivos del fenómeno peronista. Buenos Aires: EUDEBA, 2003.

SLIPAK, Daniela. Las revistas montoneras: cómo la organización construyó su identidad a través de sus publicaciones. Buenos Aires: Siglo Veintiuno Editores, 2015. TARCUS, Horacio. La secta política. ENsayo acerca de la pervivencia de lo sagrado en la modernidad. El Rodaballo, Buenos Aires, n. 9, p. 22-33, verano 1998-1999.

TARCUS, Horacio. Notas para una critica de la razón instrumental. A proposito del debate en torno de la carta de Oscar del Barco. Políticas de la Memoria, Buenos Aires, n. 6-7, 2006, p.14-26.

\section{GANPHLAC}

